\title{
ALS2-related disorders in Spanish children
}

\author{
Enrique Nogueira $^{1,2}$ (D) Juana Alarcón ${ }^{3} \cdot$ Carmen Garma $^{1,2} \cdot$ Cecilia Paredes $^{3}$
}

Received: 13 July 2020 / Accepted: 10 November 2020 / Published online: 7 January 2021

(C) The Author(s) 2021

\begin{abstract}
$A L S 2$ gene encoding for alsin protein is responsible for neurological disorders due to retrograde degeneration of the upper motor neurons of the pyramidal tracts, inherited in an autosomal recessive manner, and displaying a clinical continuum including the infantile ascending hereditary spastic paraplegiaidentified in three Spanish children presented here.
\end{abstract}

Keywords ALS2 · ALS2-related disorders · Infantile ascending hereditary spastic paraplegia $\cdot$ IAHSP · Spanish children

Dear Editor-in-Chief,

We hereby report on three ALS-like cases in Spanish children linked to gene ALS2 (alsin Rho guanine nucleotide exchange factor ALS2) of 2q33.1 encoding alsin protein. ALS2related disorders are considered a consequence of retrograde degeneration of upper motor neurons (UMN) of pyramidal tracts displaying a clinical continuum with infantile to juvenile onset and a recessive inheritance pattern, ranging from IAHSP (infantile ascending hereditary spastic paraplegia) and JPLS (juvenile primary lateral sclerosis), both primarily assigned to UMN, to JALS (juvenile amyotrophic lateral sclerosis), with additional lower motor neuron (LMN) involvement $[1,2]$.

The prevalence of $A L S 2$ disorders is unknown, with only a few cases having been described in a variety of ethnic backgrounds including Caucasians. Among the latter, the first Spanish patients reported hereby were three children of nonconsanguineous parents, from Castilla La Mancha (two sibs in family 1, F1) and the Basque Country (case in family 2, F2). ALS2 mutations were initially discovered in F1 index case and the F2 case submitted to a genome analysis for spastic paraplegia undertaken by next generation sequencing (NGS) with the use of the TruSight One Sequencing Panel (https://www.illumina.com), leading to identification of two compound heterozygous genotypes, that clearly underneath

Enrique Nogueira

enrique.nogueira@gmail.com

1 Molecular Diagnostics Eurofins-Megalab, Hospital San Rafael, Madrid, Spain

2 Genetics Service, Hospital La Zarzuela, Madrid, Spain

3 Pediatric Neurology, Hospital San Rafael, Madrid, Spain disease, of ALS2 mutations Q982SfsX19 and R704X in F1 and R640X and G49R in F2. They are presented in Figs. 1 and 2 with the available clinical data of the patients as well as in Fig. 3 to show its location in the alsin sequence together with many of the ALS2 mutations described from 2001 to 2018 [3-20].

F1 mutations Q982SfsX19 and R704X have been identified for the first time as far as we know. However, they are considered pathogenic taking into account their deleterious nature, location, and familial segregation. They are indeed frameshift (Q982SfsX19, paternal derived) and nonsense (R704X, maternal) variants like most of pathogenic $A L S 2 \mathrm{mu}-$ tations that predict truncated defective proteins and are located in $\mathrm{DH} / \mathrm{PH}$ domain near to pathogenic variants of similar type such as E724GfsX26 and Q715X. Of these, E724GfsX26 was described with variant $\mathrm{G} 437 \mathrm{Vfs} \mathrm{X} 9$ of $\mathrm{RCC} 1$ domain in a compound heterozygous genotype in two Chinese siblings with IAHSP [18], whereas the homozygous nonsense mutation Q715X was reported in two sibs claimed to be the first IAHSP cases from northwestern Europe [12]. Besides, the pathogenic nature of $A L S 2 \mathrm{~F} 1$ mutations is pointed out by its segregation. Each mutation is clinically silent in the parents but together in a compound heterozygous genotype is associated to disease in the siblings though with remarkable differences. Whereas index case would be an apparent typical IAHSP case, that of his old sister much more severe might suggest the consideration of an early-onset JPLS. A similar of severe picture has recently been observed in a young girl of Seville (Spain) homozygous for the R704X mutation (Nogueira E, unpublished).

F2 patient would be a typical IAHSP case due to a compound heterozygous ALS2 genotype of two previously reported mutations, R640X, of paternal derivation, and G49R, 


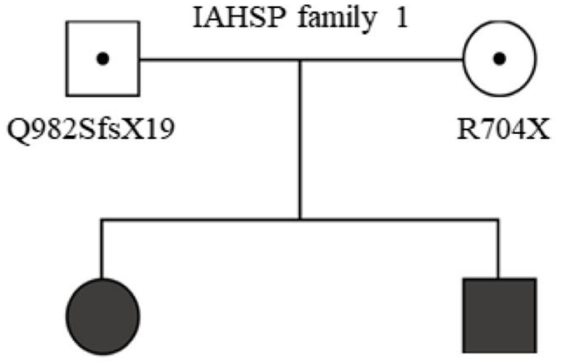

Q982SfsX19 / R704X

Onset within first year with

lower limbs weakness and spasticity, poor motor skills acquisition, never able walk without support, wheelchair need by 4 years, but normal cognitive development. Progressive deterioration with upper limb involvement (spastic tetraplegia) and dysarthria by 10 years. Normal brain MRI and nerve electrophysiology studies.

Suspected initial diagnosis: spastic diplegic cerebral palsy (presumed brain damage due to prolonged labor).
ALS2 Q982SfsX19

ALS2(NM_020919.4):c.2944delC (p.Gln982SerfsTer19) exon 17

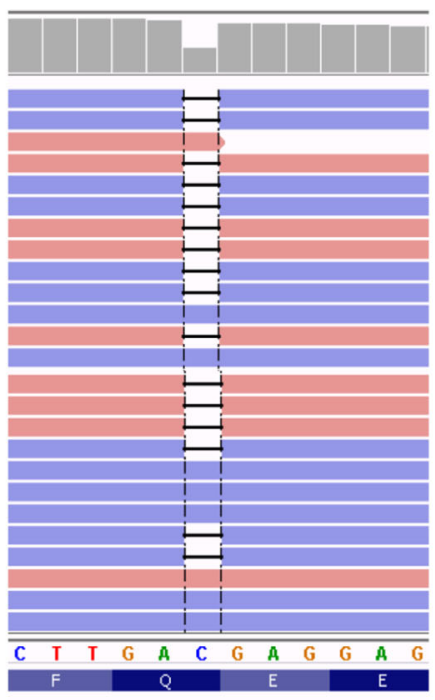

ALS2
ALS2 R704X

ALS2(NM_020919.4):c.2110C $>$ T (p.Arg704Ter) exon 10

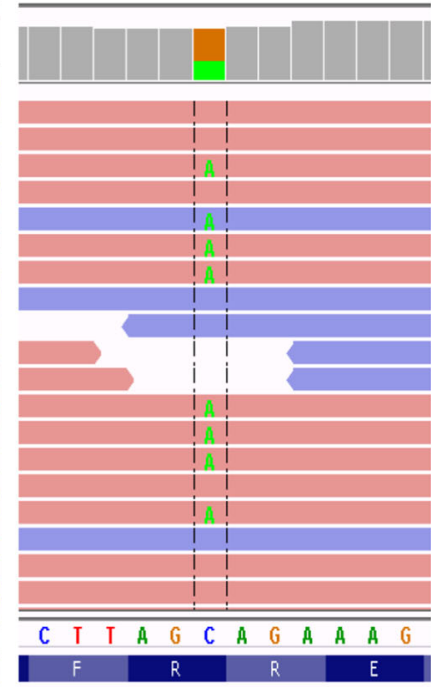

ALS2

Fig. 1 Relevant features of IAHSP family 1(F1) patients together with illustrations of ALS2 mutations

maternal. The nonsense R640X mutation that lies in a sequence between $\mathrm{RCC} 1$ and $\mathrm{DH}$ domains has been found in homozygosis in two Pakistani siblings considered IAHSP cases [19]. On the other hand, the missense mutation G49R located upstream of RCC1 domain has also been described as part of a compound heterozygous ALS2 genotype, together with mutation G477AfsX19 in a boy described as first
Portuguese IAHSP case [16]. In addition to its segregation in the Portuguese and our F2 cases, the relevant nature of G49R is suggested by its very rare occurrence (only twice in genom $A D$ databases, with $0.0004 \%$ global allelic frequency) and by affecting a very conserved residue $\left(\mathrm{Gly}^{49}\right)$ whose nonconservative substitution (by Arg) would probably have conformational and functional consequences, a presumption

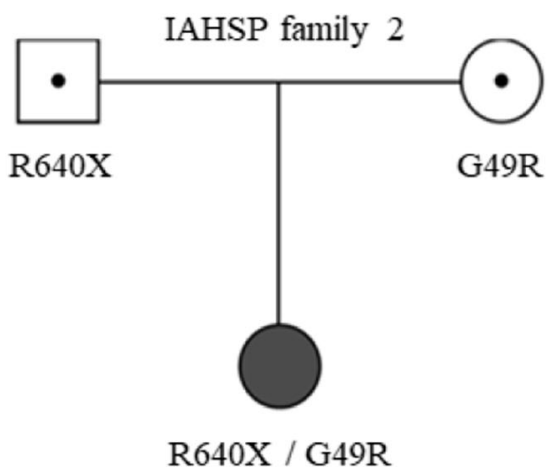

Onset at two years of age with lower limbs weakness and spasticity, hyperreflexia, clonus and extensor plantar response.

Normal acquisition of motor skills and ambulation.

By 4 years without additional findings, normal cognitive and language development.

ALS2 R640X

ALS2(NM_020919.4):c.1918C >T (p.Arg640Ter) exon 9

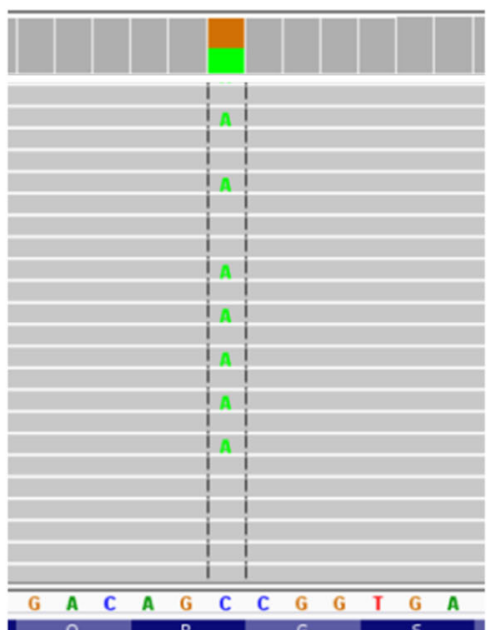

ALS2
ALS2 G49R

ALS2(NM 020919.4):c.145G $>$ A (p.Gly49Arg) exon 3

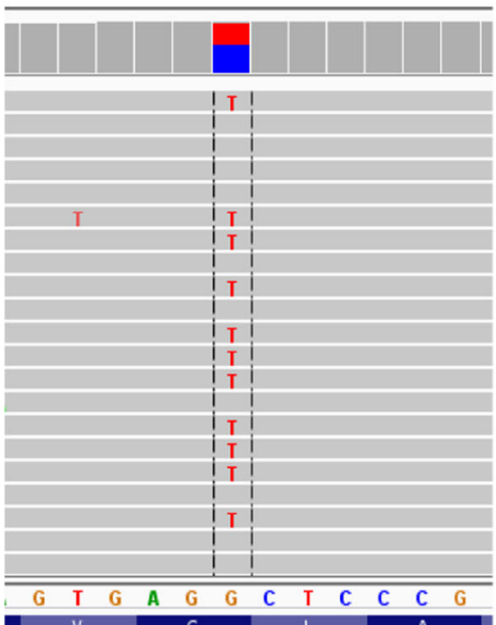

ALS2

Brain MRI with normal findings.

Suspected diagnosis: spastic paraplegia.

Fig. 2 Relevant features of IAHSP family 2 (F2) patient together with illustrations of ALS2 mutations 


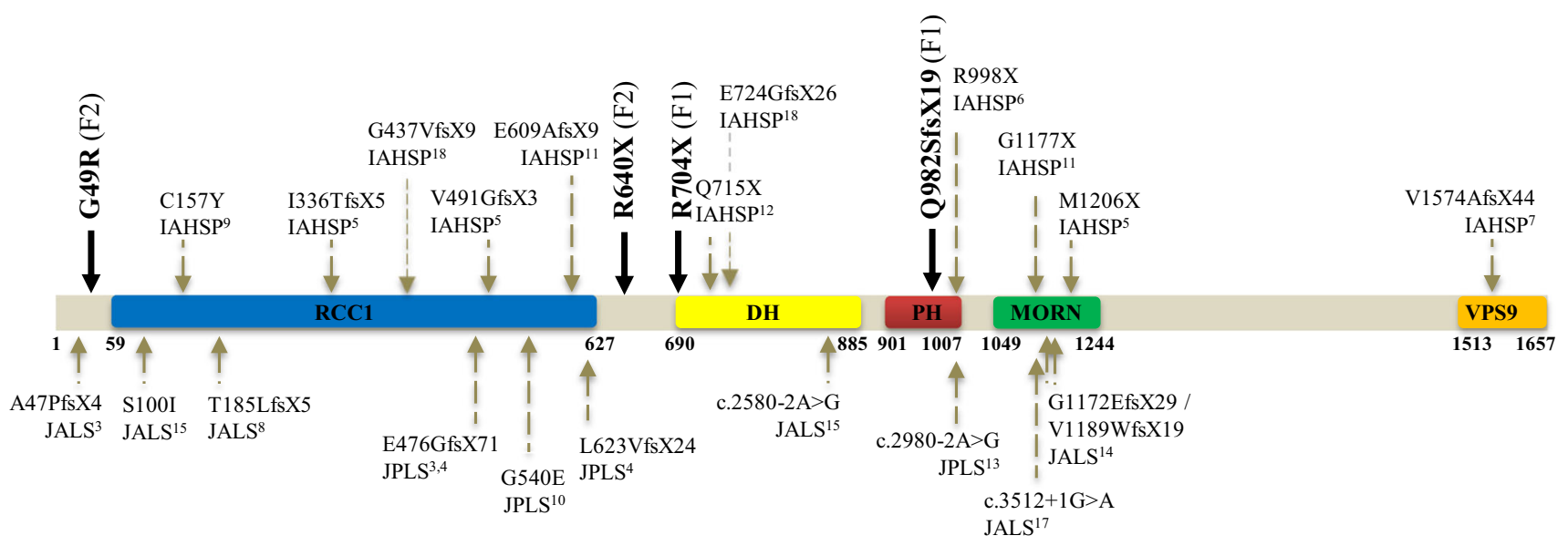

Fig. 3 Disposition of the ALS2 mutations identified in the Spanish children (in bold) and some other patients throughout the alsin sequence. Mutations G49R and R640X had previously been described in AIHSP patients ${ }^{16,19}$. IAHSP, infantile ascending hereditary spastic paraplegia; JALS, juvenile amyotrophic lateral sclerosis; JPLS,

congruent with the pathogenic prediction of a majority of in silico analyses as described in knowledge base VarSome (https://varsome.com). Thus, according to the ACMG evaluation criteria, G49R might be considered a pathogenic or likely pathogenic variant. It would increase the small number of missense variants described in different $A L S 2$ disorders, such as S100I, C157Y, and G540E with proposed association to cases of JALS, IAHSP, and JPLS, respectively (Fig. 3). According to recent data, the pathogenic nature of missense mutations would be due to altered oligomerization and/or destabilization of the mutant alsin molecules impairing its endosomal localization [21].

The finding of $A L S 2$ mutations in our F1 and F2 families allowed a precise diagnosis of the patients despite of the scarce clinical data suggesting cases of spastic paraplegia. They would be ALS2-related disorders of the UMN spectrum, most probably of IAHSP type although considering the marked affectation differences of F1 siblings, and it is tempting to speculate that same genotype (Q982SfsX19/R704X) might be associated to different disorders, being that of index case a typical example of IAHSP whereas that of his old sister would also be compatible with diagnosis of an earlyonset JPLS. Such an observation is in line with the known intra- and interfamilial phenotypic variability of ALS2-related disorders, noted among others in 11 IAHSP patients of three unrelated consanguineous Iranian families homozygous for mutation c.1640+ $1 \mathrm{G}>\mathrm{A}$ of $A L S 2$ [20]. Of them, three siblings from one family exhibited dystonia not been in families with IAHSP, only previously described in unrelated consanguineous families with JALS/ALS2 [16, 20]. A marked phenotypic variability has also been observed in two juvenile primary lateral sclerosis; $\mathrm{RCC} 1$, regulator of chromatin condensation 1; DH/PH, Dbl and Pleckstrin homology; MORN: membrane occupation and recognition nexus; VPS9, vacuolar protein sorting 9

siblings homozygous for $A L S 2$ variant c.2980-2A>G, considered JPL cases, one of them began using a wheelchair at the age of two whereas the other began using it at age 50 [13].

Further, the distribution of F1 and F2 mutations as well as other $A L S 2$ mutations (illustrated by Fig. 3) is in favor of a lack of both mutation hotspots and a precise domain involvement in the different ALS2-related disorders that otherwise due to considerable clinical overlap led to divergent diagnosis, in particular of $U M N$ spectrum disorders being in some instances similar pictures called either IAHSP or JPLS [1]. These observations and the phenotypic variability of same genotypes suggest the consideration of a decisive contribution of additional factors in the pathogenesis of $A L S 2$ disorders, mainly of genes coding for molecules interacting with alsin along its multiple functions, particularly in the endolysosomal pathway [21], that may display functional variations due even to subtle changes, no necessarily to pathogenic variants, attributable to diversity of the genomic dotation of $A L S 2$ mutation carriers including of siblings.

\section{Compliance with ethical standards}

Conflict of interest The authors declare that they have no conflict of interests.

\section{Ethical approval None.}

Open Access This article is licensed under a Creative Commons Attribution 4.0 International License, which permits use, sharing, adaptation, distribution and reproduction in any medium or format, as long as you give appropriate credit to the original author(s) and the source, provide a link to the Creative Commons licence, and indicate if changes were 
made. The images or other third party material in this article are included in the article's Creative Commons licence, unless indicated otherwise in a credit line to the material. If material is not included in the article's Creative Commons licence and your intended use is not permitted by statutory regulation or exceeds the permitted use, you will need to obtain permission directly from the copyright holder. To view a copy of this licence, visit http://creativecommons.org/licenses/by/4.0/.

\section{References}

1. Orrell RW (1993-2017) ALS2-related disorders. 2005 Oct 21 [Updated 2016 Jan 28]. In: Adam MP, Ardinger HH, Pagon RA et al (eds) GeneReviews [Internet]. University of Washington, Seattle. Available from https://www.ncbi.nlm.nih.gov/books/ NBK1243. Accessed 8 Nov 2020

2. Brugman F, Eymard-Pierre E, van den Berg LH et al (2007) Adultonset primary lateral sclerosis is not associated with mutations in the ALS2 gene. Neurology 69:702-704

3. Hadano S, Hand CK, Osuga H, Yanagisawa Y, Otomo A, Devon RS, Miyamoto N, Showguchi-Miyata J, Okada Y, Singaraja R, Figlewicz DA, Kwiatkowski T, Hosler BA, Sagie T, Skaug J, Nasir J, Brown RH Jr, Scherer SW, Rouleau GA, Hayden MR, Ikeda JE (2001) A gene encoding a putative GTPase regulator is mutated in familial amyotrophic lateral sclerosis 2. Nat Genet 29: 166-173

4. Yang Y, Hentati A, Deng HX, Dabbagh O, Sasaki T, Hirano M, Hung WY, Ouahchi K, Yan J, Azim AC, Cole N, Gascon G, Yagmour A, Ben-Hamida M, Pericak-Vance M, Hentati F, Siddique T (2001) The gene encoding alsin, a protein with three guanine-nucleotide exchange factor domains, is mutated in a form of recessive amyotrophic lateral sclerosis. Nat Genet 29:160-165

5. Eymard-Pierre E, Lesca G, Dollet S, Santorelli FM, di Capua M, Bertini E, Boespflug-Tanguy O (2002) Infantile-onset ascending hereditary spastic paralysis is associated with mutations in the alsin gene. Am J Hum Genet 71:518-527

6. Devon RS, Helm JR, Rouleau GA, Leitner Y, Lerman-Sagie T, Lev D, Hayden MR (2003) The first nonsense mutation in alsin results in a homogeneous phenotype of infantile-onset ascending spastic paralysis with bulbar involvement in two siblings. Clin Genet 64 : $210-215$

7. Gros-Louis F, Meijer IA, Hand CK, Dubé MP, MacGregor DL, Seni MH, Devon RS, Hayden MR, Andermann F, Andermann E, Rouleau GA (2003) An ALS2 gene mutation causes hereditary spastic paraplegia in a Pakistani kindred. Ann Neurol 53:144-145

8. Kress JA, Kühnlein P, Winter P, Ludolph AC, Kassubek J, Müller U, Sperfeld AD (2005) Novel mutation in the ALS2 gene in juvenile amyotrophic lateral sclerosis. Ann Neurol 58:800-803

9. Eymard-Pierre E, Yamanaka K, Haeussler M, Kress W, GauthierBarichard F, Combes P, Cleveland DW, Boespflug-Tanguy O (2006) Novel missense mutation in ALS2 gene results in infantile ascending hereditary spastic paralysis. Ann Neurol 59:976-980
10. Panzeri C, De Palma C, Martinuzzi A et al (2006) The first ALS2 missense mutation associated with JPLS reveals new aspects of alsin biological function. Brain 129:1710-1719

11. Sztriha L, Panzeri C, Kálmánchey R, Szabó N, Endreffy E, Túri S, Baschirotto C, Bresolin N, Vekerdy Z, Bassi MT (2008) First case of compound heterozygosity in ALS2 gene in infantile-onset ascending spastic paralysis with bulbar involvement. Clin Genet 73: 591-593

12. Verschuuren-Bemelmans CC, Winter P, Sival DA, Elting JW, Brouwer OF, Müller U (2008) Novel homozygous ALS2 nonsense mutation (p.Gln715X) in sibs with infantile-onset ascending spastic paralysis: the first cases from northwestern Europe. Eur J Hum Genet 16:1407-1411

13. Mintchev N, Zamba-Papanicolaou E, Kleopa KA, Christodoulou K (2009) A novel ALS2 splice-site mutation in a Cypriot juvenileonset primary lateral sclerosis family. Neurology 72:28-32

14. Shirakawa K, Suzuki H, Ito M, Kono S, Uchiyama T, Ohashi T, Miyajima H (2009) Novel compound heterozygous als2 mutations cause juvenile amyotrophic lateral sclerosis in Japan. Neurology 73:2124-2126

15. Luigetti M, Lattante S, Conte A, Romano A, Zollino M, Marangi G, Sabatelli M (2013) A novel compound heterozygous ALS2 mutation in two Italian siblings with juvenile amyotrophic lateral sclerosis. Amyotroph Lateral Scler Frontotemporal Degener 14:470-472

16. Flor-de-Lima F, Sampaio M, Nahavandi N (2014) Alsin related disorders: literature review and case study with novel mutations. Case Rep Genet 2014:691515

17. Siddiqi S, Foo JN, Vu A, Azim S, Silver DL, Mansoor A, Tay SKH, Abbasi S, Hashmi AH, Janjua J, Khalid S, Tai ES, Yeo GW, Khor CC (2014) A novel splice-site mutation in ALS2 establishes the diagnosis of juvenile amyotrophic lateral sclerosis in a family with early onset anarthria and generalized dystonias. PLoS One 9: e113258

18. Xie F, Cen ZD, Xiao JF, Luo W (2015) Novel compound heterozygous ALS2 mutations in two Chinese siblings with infantile ascending hereditary spastic paralysis. Neurol Sci 36:1279-1280

19. Tariq H, Mukhtar S, Naz S (2017) A novel mutation in ALS2 associated with severe and progressive infantile onset of spastic paralysis. J Neurogenet 31:26-29

20. Helal M, Mazaheri N, Shalbafan B, Malamiri RA, Dilaver N, Buchert R, Mohammadiasl J, Golchin N, Sedaghat A, Mehrjardi MYV, Haack TB, Riess O, Chung WK, Galehdari H, Shariati G, Maroofian R (2018) Clinical presentation and natural history of infantile-onset ascending spastic paralysis from three families with an ALS2 founder variant. Neurol Sci 39:1917-1925

21. Sato K, Otomo A, Ueda MT, Hiratsuka Y, Suzuki-Utsunomiya K, Sugiyama J, Murakoshi S, Mitsui S, Ono S, Nakagawa S, Shang HF, Hadano S (2018) Altered oligomeric states in pathogenic ALS2 variants associated with juvenile motor neuron diseases cause loss of ALS2-mediated endosomal function. J Biol Chem 293:1713517153

Publisher's note Springer Nature remains neutral with regard to jurisdictional claims in published maps and institutional affiliations. 